\title{
Dietary fat and carbohydrate have different effects on body weight, energy expenditure, glucose homeostasis and behaviour in adult cats fed to energy requirement
}

\author{
Margaret A. Gooding ${ }^{1,2}$, Jim L. Atkinson ${ }^{1}$, Ian J. H. Duncan ${ }^{1}$, Lee Niel $^{3}$ and Anna K. Shoveller ${ }^{1,2} *$ \\ ${ }^{1}$ University of Guelph, Animal and Poultry Science, Guelph, Ontario, Canada N1G 2W1 \\ ${ }^{2}$ Procter and Gamble Pet Care, Mason, OH 45040, USA \\ ${ }^{3}$ Ontario Veterinary College, Population Medicine, Guelph, Ontario, Canada N1G 2W1
}

(Received 23 January 2014 - Final revision received 16 October 2014 - Accepted 20 October 2014)

Journal of Nutritional Science (2015), vol. 4, e2, page 1 of 6

doi:10.1017/jns.2014.60

Abstract

The effects of dietary carbohydrate and fat on feline health are not well understood. The effects of feeding diets moderately high in fat (HF; $n 10 ; 30 \%$ fat, $26 \%$ carbohydrate as fed) or carbohydrate (HC; $n 10 ; 11 \%$ fat, $47 \%$ carbohydrate), for $84 \mathrm{~d}$, were investigated in healthy, adult cats (3.5 (SD 0.5$)$ years). Data on indirect calorimetry, blood biomarkers, activity, play and cognition were collected at baseline, and at intervals throughout the study. Body composition was measured by dual-energy X-ray absorptiometry at baseline and on day 85. There were no significant main effects of diet on body weight and composition. When data were analysed over study day within diet, cats fed HF diets experienced a significant increase in body fat $(P=0.001)$ and body weight $(P=0.043)$ in contrast to cats consuming the HC diet that experienced no change in body fat or body weight $(P=0.762)$ throughout the study. Overall, energy expenditure was similar between diets $(P=0.356$ (fasted), $P=0.086$ (postprandial)) and respiratory quotient declined with exposure to the HF diet and increased with exposure to the HC diet $(P<0.001$; fasted and postprandial). There was no difference in insulin sensitivity as an overall effect of diet $(P=0 \cdot 266)$. Activity declined from baseline with exposure to both diets (HC: $P=0 \cdot 002$; HF: $P=0 \cdot 01)$ but was not different between diets $(P=0 \cdot 247)$. There was no effect of diet on play $(P=0.387)$ and cats consuming either the HF or HC diet did not successfully learn the cognitive test. Overall, cats adapt to dietary macronutrient content, and the implications of feeding HC and HF diets on risk for adiposity as driven by metabolic and behavioural mechanisms are discussed.

Key words: Indirect calorimetry: Energy expenditure: Activity: Play: Cognition: Macronutrients: Insulin

Approximately $50 \%$ of cats (Felis catus) are overweight or obese in the $\mathrm{USA}^{(1)}$. Macronutrient distribution in the diet, namely diets high in fat or carbohydrate, as a percentage of energy, have been identified as risk factors for weight gain ${ }^{(2,3)}$ and remains a controversial area. For domestic cats, it remains unclear as to whether a high-carbohydrate (HC) or high-fat (HF) diet poses the greatest risk for the development of obesity and diabetes as both have been shown to contribute to adiposity and perturbations in glucose and insulin handling ${ }^{(4-6)}$. Further, metabolic effects of $\mathrm{HF}$ and $\mathrm{HC}$ diets, as observed in human subjects and rodent species, may be compounded by behavioural impacts that contribute to lethargy, impaired cognitive skills and reduced satiety, via specific brain responses, all factors that may increase the risk for weight gain ${ }^{(7-9)}$.

The objectives of the present investigation were to examine the metabolic and behavioural effects of feeding cats $\mathrm{HF}$ or HC diets for $84 \mathrm{~d}$. We hypothesised that feeding a HC diet would lead to outcomes related to insulin insensitivity, but within the time frame of the present study, no improvements in behavioural outcomes.

Abbreviations: BMC, bone mineral content; BW, body weight; DXA, dual-energy X-ray absorptiometry; EE, energy expenditure; G:I, glucose:insulin; HC, high carbohydrate; $\mathrm{HF}$, high fat; LBM, lean body mass; ME, metabolisable energy; RQ, respiratory quotient.

* Corresponding author: Anna Kate Shoveller, email kate.shoveller@effem.com 


\section{Materials and methods}

All procedures were reviewed and approved by the Institutional Animal Care and Use Committee at Procter \& Gamble Pet Care.

\section{Animals and housing}

A group of twenty cats of similar age $(3.5$ (SD 0.5$)$ years), ten female and ten males, were provided by the Pet Health and Nutrition Center at Procter and Gamble Pet Care, Lewisburg, OH, USA. Veterinarian evaluation indicated that all cats entered the study healthy. Outside of calorimetry collection, cats were housed in a free-living group environment. On indirect calorimetry days, cats were temporarily housed in respiration calorimetry chambers (Qubit Systems ${ }^{\circledR}$ ) made of Plexiglas and measuring $53.3 \times 53.3 \times 76.2 \mathrm{~cm}$. Cats had been previously acclimatised to chambers over an 11-week period of increasing exposure ${ }^{(10)}$ and routinely exposed to maintain acclimatisation.

\section{Diets}

$\mathrm{HF}$ and $\mathrm{HC}$ diets were formulated similarly on an ingredient and nutrient content basis as a percentage of energy, had similar dietary protein:metabolisable energy (ME) ratios (Table 1), and were fed to equal ME as a function of body weight (BW) (females $=189 \mathrm{~kJ} \mathrm{ME} / \mathrm{kg} \mathrm{BW}$ per d; males $=209 \mathrm{~kJ} \mathrm{ME} / \mathrm{kg}$ BW per $\mathrm{d})^{(11)}$. Feeding in this manner avoids confounding effects due to differences in absolute protein and energy intake ${ }^{(12)}$. The dietary nutrient content of each diet was determined before the start of the study using duplicates and AOAC ${ }^{(13)}$ procedures for DM (934.01), CP (990.03), acidhydrolysed fat (954.02), fibre (962.09), starch (979.10), ash (942.05), P (964.06) and Ca (968.08). Dietary gross energy was determined using an automated bomb calorimeter (IKA C-2000; IKA Works, Inc.). Cats were fed individually at 07.00 hours and allowed $60 \mathrm{~min}$ to consume the meal. Remaining feed was collected and weighed and daily energy intakes recorded for each cat. The washout diet fed during baseline collections was Iams ${ }^{\circledR}$ Original Chicken diet.

\section{Experimental design}

For 3 weeks, all cats were fed the washout diet and subjected to baseline measurements. After baseline collections cats were blocked based on body condition and sex and allocated to either a HF or HC dietary treatment for $84 \mathrm{~d}$. On days -7 , 35 and 76 , cats were subjected to $22 \mathrm{~h}$ indirect calorimetry measurements and upon removal from the chambers blood $(3.5 \mathrm{ml})$ was sampled. On days $-14,28$ and 70, activity was measured, on days -20 and 64, play motivation was measured, and on days $-1,42$ and 84, cognitive function was measured. BW was measured weekly and feed intake daily. Body composition was measured using dual-energy X-ray absorptiometry (DXA) on day -21 of the washout diet and on day 85 for all cats.
Table 1. Ingredient composition $(\mathrm{g} / \mathrm{kg})$ and analysed nutrient contents (\% of metabolisable energy; ME) of the high-fat (HF) and highcarbohydrate $(\mathrm{HC})$ diets (as-fed)

\begin{tabular}{|c|c|c|}
\hline Diet... & HF & $\mathrm{HC}$ \\
\hline \multicolumn{3}{|l|}{ Ingredient (g/kg) } \\
\hline Chicken by-product meal & $440 \cdot 7$ & 291.4 \\
\hline Maize, yellow & $179 \cdot 9$ & $277 \cdot 6$ \\
\hline Chicken fat & $182 \cdot 1$ & $20 \cdot 0$ \\
\hline Maize grits & - & $228 \cdot 8$ \\
\hline Sorghum grain & $60 \cdot 0$ & $92 \cdot 5$ \\
\hline Beet pulp & $24 \cdot 7$ & $25 \cdot 6$ \\
\hline Fish oil & 23.4 & 3.6 \\
\hline Chicken flavour & $19 \cdot 0$ & $19 \cdot 0$ \\
\hline Dicalcium phosphate & $14 \cdot 7$ & $19 \cdot 6$ \\
\hline Dried egg & 9.9 & $10 \cdot 2$ \\
\hline Sodium bisulfate & $8 \cdot 0$ & $8 \cdot 0$ \\
\hline Potassium chloride & $6 \cdot 7$ & $6 \cdot 3$ \\
\hline Mineral premix* & $5 \cdot 0$ & $5 \cdot 0$ \\
\hline Yeast, brewers & 4.9 & $5 \cdot 1$ \\
\hline Calcium carbonate & $4 \cdot 2$ & $5 \cdot 3$ \\
\hline Choline chloride & 3.9 & $3 \cdot 1$ \\
\hline DL-Methionine $†$ & 0 & 0.9 \\
\hline Vitamin premix $\ddagger$ & 1.6 & $1 \cdot 0$ \\
\hline \multicolumn{3}{|l|}{ Analysed nutrient content (\%) } \\
\hline Moisture & $8 \cdot 0$ & $8 \cdot 0$ \\
\hline Protein & $34 \cdot 0$ & $30 \cdot 0$ \\
\hline Fat & $30 \cdot 0$ & 11.0 \\
\hline Crude fibre & 1.0 & 1.5 \\
\hline Ash & $5 \cdot 0$ & $6 \cdot 0$ \\
\hline NFE§ & $25 \cdot 8$ & $47 \cdot 1$ \\
\hline Calculated ME (kJ/kg)川 & 19907 & 15631 \\
\hline Protein (g/kg):ME (kJ/kg)ף & 0.002 & 0.002 \\
\hline
\end{tabular}

$\mathrm{NFE}, \mathrm{N}$-free extract; ppm, parts per million.

${ }^{*}$ Mineral premix contained: $40.4 \%$ K, 38.1\% Cl; 3500 ppm Cu; 16120 ppm Mn; 60 $000 \mathrm{Zn} ; 420$ ppm I; 150 ppm Co.

† Diets were formulated to contain $1.150 \mathrm{~g}$ DL-methionine $/ \mathrm{kg}$.

‡ Vitamin premix contained: $36300 \mathrm{kJU} / \mathrm{kg}$ vitamin A; $1725000 \mathrm{IU} / \mathrm{kg}$ vitamin $\mathrm{D}_{3}$; 148650 IU/kg vitamin E; 22575 ppm thiamine; 89130 ppm niacin; 19200 ppm pyridoxine; $25935 \mathrm{ppm}$ pantothenic acid; $2430 \mathrm{ppm}$ folic acid; $189 \mathrm{ppm}$ vitamin $\mathrm{B}_{12}$; 5520 ppm inositol; 54000 ppm vitamin C; 540 ppm biotin; 5940 ppm riboflavin.

$\S \mathrm{NFE}=100-$ (crude protein + crude fat + crude fibre + moisture + ash $)^{(10)}$.

II ME was calculated from guaranteed analysis and the modified Atwater equation $(\mathrm{ME}(\mathrm{kJ} / \mathrm{kg})=(14.6 \times \mathrm{kg} \mathrm{NFE})+(35.6 \times \mathrm{kg} \text { fat })+(14.6 \times \mathrm{kg} \text { protein }))^{(11)}$.

ๆ Diets were formulated to contain the same protein:energy ratio.

\section{Body composition}

For DXA, animals were anaesthetised with an intramuscular injection of Dexdomitor ${ }^{\circledR}$ (Pfizer Corp.) in combination with Hydromorphone $^{\circledR} \quad$ (Baxter Healthcare Corp.). Three DXA scans were completed for each cat and data averaged (Hologic Inc.). Once the scans were completed, an intramuscular injection of a reversal agent Antisedan ${ }^{\circledR}$ (Pfizer Corp.) was administered.

\section{Indirect calorimetry and blood metabolites}

To assess the effects of diet, indirect calorimetry, a validated technique for the measurement of resting energy expenditure (EE) in cats ${ }^{(14)}$, was used to measure respiratory gas exchange to calculate EE and respiratory quotient $(\mathrm{RQ})^{(15)}$. Fasted blood metabolites measured included: glucose and insulin. Indirect calorimetry and blood sampling procedures have been described previously ${ }^{(16)}$.

\section{Behavioural assessments}

Voluntary activity was measured using Actical ${ }^{\circledR}$ activity monitors (Mini Mitter) that were worn parallel to the ribs and 
attached via a harness for $24 \mathrm{~h}$. The Actical ${ }^{\circledR}$ software analysed and converted the data into arbitrary numbers referred to as activity counts per designated time period (15 s).

Play motivation was measured $6 \mathrm{~h}$ post-feeding using an obstruction test ${ }^{(17)}$. Two boxes (width $100 \mathrm{~cm}$, length $100 \mathrm{~cm}$, height $75 \mathrm{~cm}$; Queen City Polymers), one start box and one goal box, were connected via a swing door (width $23 \mathrm{~cm}$, height $18 \mathrm{~cm})$ made of $1.9 \mathrm{~cm}$ (1/16 feet) Plexiglas which is similar to the doors that are in the group housing to access outside. To assess play motivation, the swing door was made progressively more difficult to open through the addition of weights (maximum $600 \mathrm{~g}$ ). When the cat pushed at the weighted door with sufficient force the cat could pass underneath the door to enter the goal box where interaction with a toy mouse was permitted for $30 \mathrm{~s}$. The maximum door weight that each cat would push to enter the goal box was measured.

A T-maze (stem: length $2.13 \mathrm{~m}$ (7 feet), width $0.46 \mathrm{~m}(1.5$ feet), height $0.46 \mathrm{~m}$ ( 1.5 feet); arm: length $0.99 \mathrm{~m}(3.25$ feet), width $0.46 \mathrm{~m}$ ( 1.5 feet), height $0.46 \mathrm{~m}(1.5$ feet $))$ was used to measure cognitive function $6 \mathrm{~h}$ post-feeding. All cats were acclimatised to the T-maze and associated testing before the study. A spatial cue (a circle and letter ' $\mathrm{x}$ ') was randomly assigned as a positive (rewarded) and negative (non-rewarded) cue for each cat and balanced for diet. Ten trials per day were used to measure the number of correct arm entries. Both arms were baited with $1 \mathrm{~g}$ of food to ensure that olfactory cues did not influence performance; however, food was only accessible to cats if they entered the correct arm containing that cat's positive (rewarded) cue.

\section{Statistical analysis}

All statistical analyses were performed using SAS (version 9.1; SAS Institute Inc. $)^{(18)}$. Mixed-effect models were fitted using the PROC MIXED function and the dependent variables were analysed using repeated measures where the fixed effects were diet and day and the random variable was cat. Denominator df were calculated using the Kenward-Rogers approximation. Repeated measures were analysed using the covariance matrix that had the smallest Akaike information criterion value and multiple comparisons were made using the Tukey-Kramer method. Fixed (main) effects of diet, day and diet $\times$ day interactions are reported; in addition, all significant or trending effects of diet $\times$ day for differences of least-squares means are discussed. Differences were considered significant at $P<0.05$. All data are represented as least squares means with their pooled standard errors.

\section{Results and discussion}

\section{Body weight and composition}

There were no significant main effects of diet, day and diet $X$ day on BW and lean body mass (LBM); however, there was an overall significant effect of day on total body fat $(P>0.05)$, with no significant main effect of diet and $\operatorname{diet} \times$ day. When specific effects within diet across day were reviewed, an increase in BW $(P=0.043$; day $-21(4.76($ SEM 0.39$) \mathrm{kg}$ ) v. day $85(4.9$ (SEM 0.44) $\mathrm{kg}$ )) occurred for cats fed the HF diet, but not the HC diet $(P=0.762$; day -21 (4.91 (SEM $0.39) \mathrm{kg}) v$. day $85(4.89($ SEM 0.44$) \mathrm{kg}))$. This was due to an increase in body fat $(P=0.001$; day $-21(0.74($ SEM 0.22$) \mathrm{kg}$ ) $v$. day $85(1.00($ SEM 0.23$) \mathrm{kg}))$ and trend towards a decline in LBM and bone mineral content (BMC) $(\mathrm{LBM}+\mathrm{BMC})$ $(P=0.071$; day $-21(4.01($ SEM $0 \cdot 2) \mathrm{kg}) v$. day $85(3.91$ (SEM $0.2) \mathrm{kg}$ )) in the cats fed the HF diet. As ME (calculated) intake did not differ over day $(P>0.05)$ or between diet $(P=0.821$; HC (171.46 (SEM 7.61) kJ/kg BW per d) $v$. HF (168.95 (SEM $7 \cdot 61) \mathrm{kJ} / \mathrm{kg} \mathrm{BW}$ per d)), the changes in body composition were caused by differences in macronutrient composition as a main effect of diet only $(P<0.001$; fat $(69.04$ (SEM 4.1) $\mathrm{kJ} / \mathrm{kg}^{0.67}$ per $\mathrm{d}$ for HC $v .161 .08$ (SEM 4.1$) \mathrm{kJ} / \mathrm{kg}^{0.67}$ per d for HF) and carbohydrate (144.35 (SEM 4.1 ) $\mathrm{kJ} / \mathrm{kg}^{0.67}$ per d for HC v. 62.76 (SEM 4.1) kJ/ $\mathrm{kg}^{0.67}$ per $\mathrm{d}$ for HF)). The present study agrees with previous results where cats had a greater risk for weight gain when fed HF $v$. HC diets either ad libitum $^{(5,19)}$ or to energy requirements ${ }^{(4,6)}$. In addition, these results further support the hypothesis that using calculated values of ME systemically underestimates the true ME content of commercially available HF diets for cats ${ }^{(20)}$; therefore, it is unclear as to whether the increase in BW and body fat with $\mathrm{HF}$ dietary feeding was driven by fat or energy intake or both. Furthermore, the trend in a reduction in LBM + BMC require further investigation as the mechanism for a loss in structural protein is surprising and may suggest that, compositionally, more protein as a function of energy content should be considered.

\section{Macronutrient metabolism}

There was a significant main effect of diet and diet $\times$ day $(P<0 \cdot 05)$, with no significant effect of day $(P=0.679)$, on fasted RQ. For cats consuming the HF diet, postprandial RQ increased from day 35 to day 76 when the effect of day was compared within dietary treatments $(P=0.022$; Table 2$)$; as such, there was a significant main effect of diet, day and $\operatorname{diet} \times$ day for postprandial RQ $(P<0 \cdot 05)$. Fasted EE was not different between diets $(P=0.356)$ and there was no main effect of diet $\times$ day $(P=0.697)$; however, there was a significant main effect of day $(P=0.001)$ which can be explained by the observed transient increase in fasted EE on day 35 (Table 2), an effect hypothesised to be due to an external environmental influence or as a function of dietary adaptation. There was a trend towards a main effect of diet on postprandial EE $(P=0.086)$ with a significant main effect of day $(P=0.013)$ and no effect of $\operatorname{diet} \times \operatorname{day}(P=0.588)$. While postprandial EE was similar over the diet treatment period for cats fed the HC diet, postprandial EE decreased over the treatment period for cats fed the HF diet $(P<0 \cdot 05$; Table 2). Overall, with the HF diets the lower fasted and postprandial RQ suggest a partial increase in lipid use for energy as a proportion of all macronutrients; however, the decline in postprandial EE with increased length of exposure to the diet may have resulted in a positive energy balance and explain the increase in body fat. The decrease in EE is probably compounded by the tendency for LBM to decrease in cats fed HF 
Table 2. Respiratory quotient (RQ), energy expenditure (EE) and blood metabolites in cats after exposure to high-fat (HF) and high-carbohydrate (HC) diets†

(Least-square means (LSM) with their pooled standard errors; $n$ 10)

\begin{tabular}{|c|c|c|c|c|c|c|c|c|}
\hline & \multirow[b]{2}{*}{ Day } & \multirow{2}{*}{$\begin{array}{c}\mathrm{HC}\left(\begin{array}{l}n \\
10)\end{array}\right. \\
\text { LSM }\end{array}$} & \multirow{2}{*}{$\begin{array}{c}\mathrm{HF}(n 10) \\
\text { LSM }\end{array}$} & \multirow[b]{2}{*}{ SEM (pooled) } & \multirow[b]{2}{*}{$P_{\text {diet(day) }}$} & \multicolumn{3}{|c|}{ Main effectsł } \\
\hline & & & & & & $P_{\text {diet }}$ & $P_{\text {day }}$ & $P_{\text {dietxday }}$ \\
\hline \multirow[t]{3}{*}{$\mathrm{RQ}$ fasted for $24 \mathrm{~h}$} & -7 & $0.791^{\mathrm{b}}$ & $0.791^{\mathrm{a}}$ & 0.01 & 1.00 & 0.001 & 0.679 & 0.003 \\
\hline & 35 & $0.814^{\mathrm{a}}$ & $0.763^{\star b}$ & 0.01 & $<0.0001$ & & & \\
\hline & 76 & $0.814^{a}$ & $0.755^{\star \mathrm{b}}$ & 0.01 & $<0.0001$ & & & \\
\hline \multirow[t]{3}{*}{$R Q$ postprandial average } & -7 & $0.834^{b}$ & $0.832^{\mathrm{a}}$ & 0.002 & 0.724 & $<0.001$ & 0.001 & $<0.001$ \\
\hline & 35 & $0.860^{\mathrm{a}}$ & $0.774^{\star c}$ & 0.004 & $<0.0001$ & & & \\
\hline & 76 & $0.863^{\mathrm{a}}$ & $0.791^{\star b}$ & 0.007 & $<0.0001$ & & & \\
\hline \multirow[t]{3}{*}{ EE fasted for $24 \mathrm{~h}\left(\mathrm{~kJ} / \mathrm{kg}^{0.67}\right.$ per d)§ } & -7 & $295 \cdot 8^{\mathrm{b}}$ & $277 \cdot 8^{\mathrm{b}}$ & $15 \cdot 5$ & 0.546 & 0.356 & 0.001 & 0.697 \\
\hline & 35 & $319 \cdot 7^{a}$ & $303.8^{a}$ & $17 \cdot 2$ & 0.644 & & & \\
\hline & 76 & $310 \cdot 9^{a, b}$ & $284 \cdot 1^{\mathrm{b}}$ & $15 \cdot 1$ & 0.497 & & & \\
\hline \multirow{3}{*}{ EE postprandial average $\left(\mathrm{kJ} / \mathrm{kg}^{0.67}\right.$ per $\left.\mathrm{d}\right) \S$} & -7 & $284 \cdot 1$ & $297 \cdot 1^{\mathrm{a}}$ & $6 \cdot 3$ & 0.178 & 0.086 & 0.013 & 0.588 \\
\hline & 35 & 285.8 & $302 \cdot 1^{\mathrm{a}}$ & $6 \cdot 3$ & 0.079 & & & \\
\hline & 76 & 273.6 & $279 \cdot 1^{\mathrm{b}}$ & $5 \cdot 0$ & 0.467 & & & \\
\hline \multirow[t]{3}{*}{ Insulin (ng/l) } & -6 & 158.4 & $163 \cdot 8^{a}$ & $19 \cdot 1$ & 0.843 & 0.215 & 0.113 & 0.067 \\
\hline & 36 & $145 \cdot 1$ & $130 \cdot 6^{\mathrm{b}}$ & 17.5 & 0.567 & & & \\
\hline & 77 & $245 \cdot 7$ & $113 \cdot 2^{a, b}$ & 57.0 & 0.118 & & & \\
\hline \multirow[t]{3}{*}{ Glucose $(\mathrm{mg} / \mathrm{dl}) \|$} & -6 & 86.4 & $86 \cdot 8^{b}$ & 1.5 & 0.852 & 0.060 & 0.160 & 0.029 \\
\hline & 36 & 83.9 & $93.0^{* a}$ & 1.4 & 0.0002 & & & \\
\hline & 77 & 89.9 & $92 \cdot 5^{\mathrm{a}, \mathrm{b}}$ & 3.5 & 0.604 & & & \\
\hline \multirow[t]{3}{*}{ G:I } & -6 & 0.61 & $0.61^{b}$ & 0.1 & 0.957 & 0.266 & 0.001 & 0.021 \\
\hline & 36 & 0.62 & $0.84^{\mathrm{a}}$ & 0.1 & 0.068 & & & \\
\hline & 77 & 0.73 & $0.90^{\mathrm{a}}$ & 0.1 & 0.325 & & & \\
\hline
\end{tabular}

G:I, glucose:insulin.

a,b,c Mean values in a column with unlike superscript letters were significantly different among day within diet $(P<0.05)$

* Mean value was significantly different from that for the $\mathrm{HC}$ diet $(P<0.05$; difference due to diet effects within day).

$\dagger P$ value refers to the ANOVA for diet within day effect and main effects of diet, day and diet $\times$ day.

$\ddagger$ Main effects of diet, day and diet $\times$ day $(P<0.05)$.

$\S$ Postprandial RQ and EE averages were calculated over $20 \mathrm{~h}$ post-feeding, with measures occurring at 30 -min intervals.

|| To convert $\mathrm{mg} / \mathrm{dl}$ to $\mathrm{mmol} / \mathrm{l}$, multiply by 0.0555 .

diets since LBM is the major predictor of non-activity-related EE. A low heat increment of feeding did not appear to influence EE since the decline in EE was only observed after longterm exposure (day 76). Thus, the decline in EE may have been due to the diversion of lipids away from oxidation towards lipogenesis as we observed a concurrent increase in $\mathrm{BW}$ and fat with an increase in RQ with long-term exposure.

\section{Blood metabolites}

There was a trend towards a significant main effect of diet on plasma glucose $(P=0.060)$, no effect of day $(P=0 \cdot 160)$ and a significant interaction effect of $\operatorname{diet} \times \operatorname{day}(P=0.029)$ on plasma glucose. Main effects were probably driven by the increase in glucose concentrations over day $(P<0.05$; Table 2) for cats fed the HF diet and the diet effect observed on day 36 as cats fed the HC diet had lower glucose concentrations than cats fed the HF diet $(P=0.001)$. Though diets were fed to an equivalent protein:ME ratio amino acids may have been transiently utilised for gluconeogenesis resulting in greater serum glucose concentrations ${ }^{(21)}$ during diet adaptation $^{(16)}$. There was no significant main effect of diet or day on insulin $(P>0.05)$; however, there was a trend towards an effect of $\operatorname{diet} \times$ day interaction $(P=0 \cdot 067)$. This trend may have been driven by the transient decline in insulin from baseline in cats fed the HF diet $(P<0.05$; Table 2). There was no significant effect of diet on glucose:insulin (G:I) $(P=0.266)$. There was a significant main effect of day and diet $\times$ day on G:I $(P<0.05)$. When G:I was analysed across day within diet treatment there was a trend towards a higher ratio with HF feeding on day $36(P=0.068$; Table 2$)$. With the consumption of the HF diet less insulin was required to normalise plasma glucose; therefore, insulin sensitivity may have been improved for cats fed the HF $v$. HC diet. However, conclusions warrant further investigation as G:I ratio provides only a gross representation of insulin sensitivity and the effects of diet on G:I were not significant and only transient for cats consuming the HF diet, suggesting dietary adaptation.

\section{Physical activity}

There were no significant main effects of diet or diet $\times$ day on physical activity $(P>0.05)$; however, there was a significant effect of day on voluntary activity $(P=0.001)$. Effects were probably driven by the decline in activity from baseline with exposure to both the HC $(P=0.002$; slope $=-1.44)$ and HF $(P=0.01$; slope $=-1.32)$ dietary treatments. A decline in voluntary physical activity is not surprising, as both diets high in carbohydrate and fat content have been shown to influence mood by reducing energy levels and alertness ${ }^{(22,23)}$; for instance, with HC dietary feeding the effects on glucose and insulin metabolism can influence the circulation of tryptophan, serotonin and the expression of brain noradrenaline transporters, decreasing the release of adrenaline that can make an impact on mood and energy ${ }^{(8,24)}$. Alternatively, HF diets, via an increase in release of cholecystokinin, a peptide hormone implicated in the mediation of postprandial sleepiness ${ }^{(25,26)}$, has been shown to promote greater feelings of lethargy ${ }^{(27)}$. 
Overall, activity declined in both dietary treatments and differences between diets may not have been observed because the cats were relatively weight stable.

\section{Play behaviour}

There were no significant main effects of diet, day or diet $x$ day on play motivation $(P>0 \cdot 05)$. Maximum door weights on day 64 were 370 (SEM 86) $g$ and 410 (SEM 86) g, for the $\mathrm{HF}$ and HC diet, respectively $(P=0 \cdot 387)$. In the domestic cat, play motivation is influenced by, but not exclusive to, hunger $^{(28)}$. Since diets high in fat and carbohydrates appear to have differing, but inconclusive, effects on satiety ${ }^{(7)}$, we may be able to hypothesise that the fat:carbohydrate ratio does not significantly influence satiety in the cat when play motivation is used as an indirect indicator of satiety or energy sensing ${ }^{(29)}$. However, measuring ad libitum intake and satiety hormones, in a study where energy intake is not controlled, is likely to provide a more direct and valid measure of the effect of macronutrient content on satiety.

\section{Cognition}

Overall, there were no significant main effects of diet, day and diet $\times$ day on cognitive performance $(P>0 \cdot 05)$. As groups were different at baseline, change from baseline was analysed and a significant main effect of diet $(P=0.041)$ on change in $\mathrm{T}$-maze performance $(\mathrm{HC}=+0.85 \nu . \mathrm{HF}=-0.85)$ was observed. However, the test was not successful as cats did not learn the task (as learning was defined as a mean score $>70 \%$ ); thus, conclusions are only speculative. It may be hypothesised that the trend for improvement in performance with HC feeding was driven by certain cognitive functions that are sensitive to short-term variations in glucose availability; however, this conclusion warrants further investigation ${ }^{(9,30)}$. While cats consuming the HF diet had higher blood glucose levels after a $24 \mathrm{~h}$ fast, the blood glucose levels at the time of testing, $6 \mathrm{~h}$ after feeding, were probably higher in the cats consuming the HC diet ${ }^{(19)}$.

\section{Conclusion}

In conclusion, cats are capable of adapting energy metabolism to different macronutrient intakes; however, after an $84 \mathrm{~d}$ feeding the diet higher in dietary fat presented a greater risk for the development of adiposity and associated metabolic effects if fed to a calculated ME allowance. It is unclear if effects are driven by total fat content of the diet or differences in energy intake, as it is understood that using calculated ME for diets high in fat may lead to an underestimation of energy density of the diet and ultimately contribute to overfeeding and increased BW and fat. Conversely, the consumption of a HC diet had minimal effects on energy metabolism and behaviour.

\section{Acknowledgements}

The authors would like to thank Cindy Lanman and Jason Brewer for their support of the data collection.
The present study was supported by Procter and Gamble Pet Care, Mason, OH 45040, USA.

A. K. S. has financial and personal interest in The Procter and Gamble Co. due to past employment with the funding company. M. A. G was a $\mathrm{PhD}$ intern and was an employee of the funding company. A. K. S. and M. A. G. are employees of The Iams Company, Mars Pet Care. I. J. H. D., L. N. and J. L. A. have no conflicts of interest.

\section{References}

1. Ward E, Budsberg S, Bartages J, et al. (editors) (2012) Big Pets Get Bigger: Latest Survey Shows US Dog and Cat Obesity Epidemic Expanding. Calabash, NC: Association for Pet Obesity Prevention.

2. Lund EM, Armstrong PJ, Kirk CA, et al. (2005) Prevalence and risk factors for obesity in adult cats from private US veterinary practices. Intern J Appl Res Vet Med 3, 388-396.

3. Slingerland LI, Vasilova VV, Plantinga EA, et al. (2009) Indoor confinement and physical inactivity rather than the proportion of dry food are risk factors for the development of feline type 2 diabetes mellitus. Vet J 179, 247-253.

4. Theiss S, Becskei C, Tomsa K, et al. (2004) Effects of high carbohydrate and high fat diet on plasma metabolite levels and on IV glucose tolerance test in intact and neutered male cats. J Felin Med Surg 6, 207-218.

5. Backus RC, Cave NJ \& Keisler DH (2007) Gonadectomy and high dietary fat but not high dietary carbohydrate induce gains in body weight and fat of domestic cats. Br J Nutr 98, 641-650.

6. Slingerland LI, Robben JH, van Haeften TW, et al. (2007) Insulin sensitivity and $\beta$-cell function in healthy cats: assessment with the use of the hyperglycemic glucose clamp. Horm Metab Res 39, 341-346.

7. Stubbs RJ, Murgatroyd PR, Goldberg GR, et al. (1993) Carbohydrate balance and the regulation of d-to-d food-intake in humans. Am J Clin Nutr 57, 897-903.

8. Watanabe H, Rose MT \& Hisashi A (2011) Role of peripheral serotonin in glucose and lipid metabolism. Curr Opin Lipidol 22, 186-191.

9. Gonzales MM, Tarumi T, Miles SC, et al. (2010) Insulin sensitivity as a mediator of the relationship between BMI and working memory-related brain activation. Obesity 18, 2131-2137.

10. Gooding MA, Duncan IJH, Atkinson JA, et al. (2012) Development and validation of a behavioural acclimation protocol for cats to respiration chambers used for indirect calorimetry studies. J Appl Anim Welf Sci 15, 144-162.

11. National Research Council (2006) Nutrient Requirements of Dogs and Cats, pp. 146-150. Washington, DC: National Academies Press.

12. Mehta S, Kalsi HK, Nain CK, et al. (1977) Energy metabolism of brain in human protein-calorie malnutrition. Pediatr Res 11, 209-293.

13. AOAC (1995) Official Methods of Analysis, 16th ed. Arlington, VA: AOAC International.

14. Center SA, Warner KL, Randolph JF, et al. (2011) Resting energy expenditure per lean body mass determined by indirect calorimetry and bioelectric impedance analysis in cats. J Vet Intern Med 25, 1341-1350.

15. Weir JBV (1949) New methods for calculating metabolic rate with special reference to protein metabolism. J Physiol 109, 1-9.

16. Gooding MA, Flickinger EA, Atkinson JA, et al. (2014) Effects of high fat and high carbohydrate diets on fat and carbohydrate oxidation and plasma metabolites in healthy cats. I Anim Physiol Anim Nutr (Berl) 98, 596-607.

17. Widowski TM \& Duncan IJH (2000) Working for a dustbath: are hens increasing pleasure rather than reducing suffering? $A p p$ Anim Behav Sci 68, 39-53.

18. SAS Institute Inc. (2008) SAS/STAT ${ }^{\circledR}$ Software. Cary, NC: SAS Institute Inc. 
19. Coradini M, Rand JS, Morton JM, et al. (2011) Effects of two commercially available feline diets on glucose and insulin concentrations, insulin sensitivity and energetic efficiency of weight gain. $\mathrm{BrJ}$ Nutr 106, Suppl. 1, S64-S77.

20. Castrillo C, Hervera M \& Baucells MD (2009) Methods for predicting the energy value of pet foods. R Bras Zootec 38, 1-14.

21. Nguyen PG, Dumon HJ, Siliart BS, et al. (2004) Effects of dietary fat and energy on body weight and composition after gonadectomy in cats. Am J Vet Res 65, 1708-1713.

22. Benton D (2002) Carbohydrate ingestion, blood glucose and mood. Neurosci Biobehav Rev 26, 293-308.

23. Wells AS, Read NW, Uvnas-Moberg K, et al. (1997) Influences of fat and carbohydrate on postprandial sleepiness, mood, and hormones. Physiol Behav 61, 679-686.

24. Figlewicz DP, Szot P, Isreal PA, et al. (1993) Insulin reduces norepinephrine transporter mRNA in vivo in rat locus caeruleus. Brain Res 602, 161-164.
25. Stacher G, Bauer H \& Steinringer H (1979) Cholecystokinin decreases appetite and activation evoked by stimuli arising from the preparation of a meal in man. Physiol Behav 23, 325-331.

26. Kapas L, Obal F \& Kruegar JM (1993) Humoral regulation of sleep. Int Rev Neurobiol 35, 131-160.

27. Wells AS, Read NW \& Craig A (1995) Influences of dietary and intraduodenal lipid on alertness, mood and sustained concentration. Br J Nutr 74, 115-123.

28. Hall SL \& Bradshaw JWS (1998) The influence of hunger on object play by the adult domestic cat. Appl Anim Behav Sci 58, 143-150.

29. Shoveller AK, Minikhiem DL, Carnagey K, et al. (2014) Low level of supplemental dietary L-carnitine increases energy expenditure in overweight, but not lean, cats fed a moderate energy density diet to maintain body weight. Intern J Appl Res Vet Med 12, 33-43.

30. Bellise F (2004) Effects of diet on behaviour and cognition in children. Br J Nutr 92, Suppl. 2, S227-S232. 